\title{
IMPORTANCE OF ELBOW FLEXOR MUSCLE STRENGTH AND ENDURANCE IN SPORTS CLIMBING
}

\author{
Michail Michailov ${ }^{1,2}$, Stanislava Lambreva $^{1}$, Diana Deneva ${ }^{1}$, \\ Hristo Andonov ${ }^{1}$ \\ ${ }^{1}$ National Sports Academy "Vassil Levski”, Sofia, Bulgaria \\ ${ }^{2}$ Medical Commission of the Union Internationale \\ des Associations d'Alpinisme (UIAA MedCom) Bern, Switzerland
}

\begin{abstract}
The muscles that exert most during sport climbing are the finger flexors followed by elbow flexors (EF). Nevertheless, climbers' EF strength and endurance have not been tested in an isolated manner and EF endurance has not been assessed at different relative intensities. Purpose: To determine the importance of EF maximal strength and endurance in sports climbing. Methods: Nine male sports climbers and a control group of seven male sports students performed an EF maximal strength (MS) test and four EF endurance tests representing isometric muscle contractions at 90\%, 70\%, $50 \%$ and $30 \%$ of the maximal voluntary contraction (MVC). Results: Sports climbers sustained longer than the controls at $70 \%\left(39 \pm 11\right.$ versus $\left.28 \pm 7 s ; p=0.044, \eta^{2}=0.259\right)$ and $50 \% M V C\left(57 \pm 10\right.$ versus $\left.48 \pm 6 s ; p=0.050, \eta^{2}=0.248\right)$. The highest effect size was

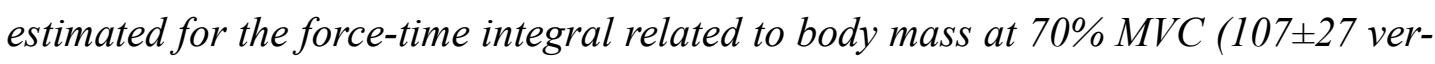
sus $\left.75 \pm 18 \mathrm{~N} . \mathrm{s} / \mathrm{kg} ; \mathrm{p}=0.018, \eta^{2}=0.338\right)$. The two groups did not differ in MS $(313 \pm 52$ versus $338 \pm 55 \mathrm{~N} ; \mathrm{p}=0.372$ ) or MS related to body mass (4.6 0.6 versus $4.2 \pm 0.8 \mathrm{~N}$ / $\mathrm{kg} ; \mathrm{p}=0.623$ ). Climbing ability significantly correlated only with MS related to body mass. The relationship between MS related to body mass and on sight ability was strong ( $r=0.806, p=0.016)$. Conclusion: EF strength and endurance appear to be key performance factors in sports climbing. Sports climbing demands a high level of EF endurance during muscle contractions of high intensity. An excessive increase of EF endurance would not necessary lead to a significant improvement in climbing ability. However, higher climbing ability demands increased EF maximal strength.
\end{abstract}

Keywords: rock climbing, isometric muscle contraction, maximal strength, muscle endurance 


\section{INTRODUCTION}

Sports climbing demands a complex development of motor abilities (Michailov, 2014). It is a whole body activity where major muscle groups of the upper extremity, trunk, and lower extremity actively contribute in order to progress on the climbing route (Phillips, Sassaman, Smoliga. 2012). Nevertheless, the rate of exertion of some muscle groups is significantly higher. The relative contribution is greater and the fatigue is deeper in finger flexor muscles followed by elbow flexor muscles (Deyhle et al., 2015; Koukoubis et al., 1995). Finger flexor muscles maintain the upper limb supports. At the same time, finger flexor muscles are small and hold significant load. Thus, climbing specific finger grip strength related to body mass correlates strongly with climbing ability and is a performance factor of major importance (Baláš et al., 2015; Grantet al., 1996; Michailov, Mladenov, Schoeffl,2009; Philippe et al., 2012). Another key performance factor is the finger flexor muscle endurance. This was evidenced in studies investigating climbing and hanging time to failure or force-time integral (FTI) from continuous or intermittent isometric contractions, which were performed using sport-specific dynamometers (Balas et al., 2012; Balas et al., 2016; MacLeod et al., 2007; Michailov, 2014; Michailov et al., 2016; Philippe et al., 2012; Vigouroux, Quaine, 2006; Fryer et al., 2015).

To be efficient, sports climbers aim to load the upper limbs as little as possible during climbing. Sports climbers can postpone the performance limiting fatigue of the muscles at the upper limbs by distributing as much as possible weight on their feet. Moreover, producing forces with the knee extensor muscles instead of using elbow flexor muscles is to be preferred when moving the center of mass higher. Nevertheless, in some climbing situations there is a great reliance on the elbow flexor muscles in order to reach the next hold. Considerable efforts of the elbow flexors cannot be avoided for example in overhanging terrain where the load at the upper limb supports increases to more than half of the climber's weight (Noé et al., 2001). Thus, several authors have found out that climbing ability is significantly related with shoulder girdle strength (Wall et al., 2004;Kodejška, Baláš, 2016) and endurance (Balas et al., 2012; Grantet al., 1996) as well as explosive strength of the upper limbs (Berrostegieta, 2006;Draper et al., 2011; Laffaye et al., 2014).

Shoulder girdle strength was estimated through arm lock-off (the climbers applied maximal force on an apparatus with the shoulder and elbow flexed at $90^{\circ}$ ) (Wall et al., 2004) or diagonal reach tests (the climbers had to reach with one hand as far as possible in the diagonal direction while maintaining a position on an overhanging wall) (Kodejška, Baláš, 2016). Shoulder girdle endurance was assessed through bent-arm hanging and explosive strength was assessed through powerful pull-ups. The results of these tests carry combined information on arm, back and shoulder strength and endurance. To the best of our knowledge, elbow flexor muscle strength and endurance have not been tested in an isolated manner. Moreover, elbow flexor endurance has not been assessed performing tests at different relative intensities prescribed as percentages of the maximal voluntary contraction (MVC).

During tests such as bent-arm hanging athletes with different body mass or maximal strength would not be placed at a similar working regime (e.g. the rela- 
tive intensity will be lower for a stronger climber compared to a weaker climber with the same body mass). Therefore, it would not be clear whether the test score reflects the muscle endurance level or is influenced by athlete's maximal strength or body mass. Muscle contraction intensity should determine the relative contribution of the aerobic and anaerobic energy systems and the number of fast muscle fibers recruited. Therefore, when evaluating muscle endurance, it is to be preferred the intensity to be set as percentage of the MVC. The performance of several elbow flexor endurance tests of different relative intensity can serve to determine the \%MVC which has the highest criterion validity with respect to climbing performance. Such investigation would bring more inside knowledge on the specific adaptation of the elbow flexors in sport climbers and may serve to create improved training plans.

Thus, the aim of the present study was to determine the importance of maximal strength and muscle endurance of the elbow flexors in sports climbing.

\section{METHODS}

\section{Participants}

Nine sport climbers (age $31.6 \pm 4.3$ years, $11.6 \pm 6$ years of climbing experience) and a control group of seven sport students (age 22.6 \pm 2.7 years) volunteered and gave informed consent to participate in the study. Climbers' reported their current climbing ability in the redpoint and on-sight styles using the IRCRA scale (Draper et al., 2015). Red point and on sight achievements were $22.0 \pm 2.4$ (range $19-26$ ) and $18.6 \pm 1.8$ (range 16 - 21), respectively. Red-point refers to climbing a route after it has been previously attempted. On-sight refers to a first try with no prior knowledge.

\section{Study design}

This study sought to bring evidence whether maximal strength and endurance of the elbow flexors are performance limiting factors in sport climbing as well as to show at which intensity climbers are adapted to perform better compared to non-climbers. This would also determine the percentage MVC that is more useful to be prescribed when evaluating climbers' elbow flexor endurance.

Therefore, the climbers and the control group performed a maximal strength test and four muscle endurance tests to assess the maximal duration of isometric contraction at $90 \%, 70 \%, 50 \%$ and $30 \%$ MVC.

\section{Methodology}

The maximal strength test and the muscle endurance tests were performed with the use of a strength measuring device 3DSAC (Balas et al., 2016) 3DSAC has a measuring range of $\pm 2 \mathrm{kN}, 0.5 \%$ accuracy, and sampling rate $125 \mathrm{~Hz}$. 3DSAC includes a guidance module, which gives real-time feedback through graphical and acoustic signals. This enabled the participants to perform the muscle endurance tests by controlling the prescribed intensity of muscle contractions. During the maximal strength test participants performed three maximal voluntary contractions separated by rest intervals of 1 minute. Maximal strength was determined by the highest force value from the three attempts. The muscle endurance tests at higher intensity preceded the tests at lower \% MVC. The test at $90 \%$ MVC was performed 5 minutes after the maximal strength test. The break before performing the test at $70 \% \mathrm{MVC}$ was 10 minutes, and the next two brakes were 20 minutes. 
The target force during the muscle endurance tests was automatically calculated. It was presented graphically along with a target zone with lower and upper limits in which the generated force could vary $\pm 10 \%$. Participants had to maintain the force within the prescribed limits for as long as possible. The software automatically stopped the endurance tests when the force dropped below the lower limit for more than one second.

All tests were performed with the right arm and in all tests elbow flexors acted isometrically. Participants were tested on a bench in a supine position with fixed right upper arm, trunk and low- er limbs (Figure 1). The right elbow was flexed at 90 degrees and the right forearm was in half supine position. Participants applied forces on 3DSAC through a metallic chain, which was horizontal to the ground and fixed on the one side at the force measuring module of 3DSAC and on the other side at the distal part of the right forearm.

Maximal strength and maximal strength related to body mass (relative strength) were registered through the maximal strength test. Parameters calculated in the muscle endurance tests were: time spent in the target zone (Ttz), FTI and FTI related to body mass.

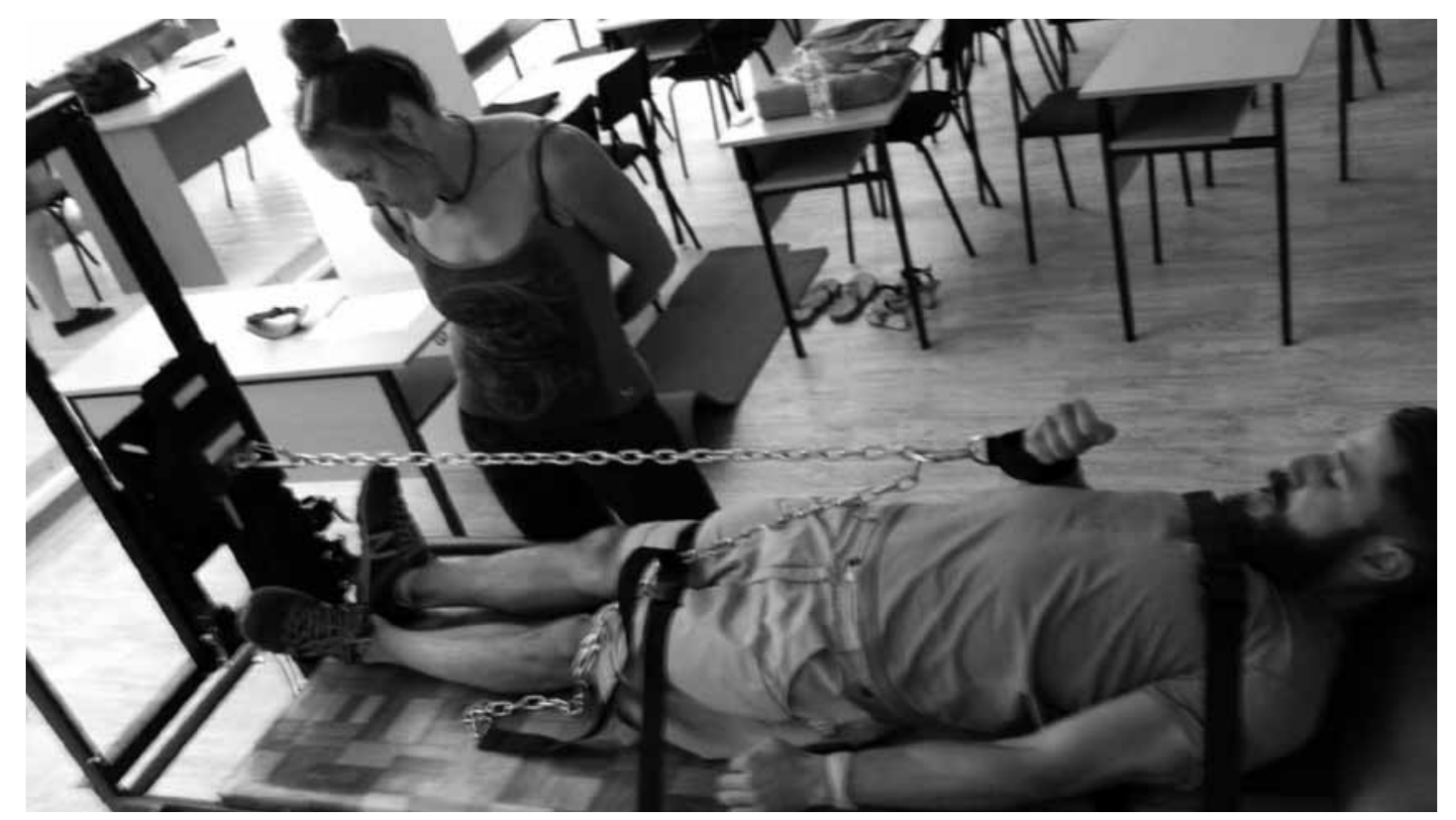

Figure 1. Body and arm position during dynamometry using $3 D S A C$

\section{Statistical analysis}

Descriptive analysis was performed to present mean values, standard deviations and confidence intervals of the measured parameters. Differences between climbers and control group were analyzed with One-Way analysis of variance (ANOVA) and effect sizes were estimated through the calculation of eta squared $\left(\eta^{2}\right)$. Statistical significance was set top $\leq 0.05$. Spearman's rank correlation coefficients were calculated to determine relationships between climbing ability variables and test results. All statistical analyses were performed with the use of SPSS 19 (IBM, New York, USA). 


\section{RESULTS}

Participants' body mass, maximal and relative strength are provided in Table 1. Sports climbers had significantly lower body mass compared to control group $(p=0.016)$ but the two groups did not differ in maximal or relative strength $(\mathrm{p}>0.05)$. Table 2 lists the results from the muscle endurance tests. Sports climbers had higher Ttz ( $\mathrm{p}$ $=0.044)$ and FTI related to body mass $(\mathrm{p}=0.018)$ at $70 \% \mathrm{MVC}$ as well as higher Ttz at 50\% MVC ( $\mathrm{p}=0.050)$ than the control group. The effect size was greater for FTI related to body mass in the endurance test at $70 \%$ MVC.No other significant differences $(p<0.05)$ were found. Climbing ability significantly correlated only with relative strength. Relative strength correlated strongly with the on-sight achievement $(r=0.806, p=0.016)$.

Table 1. Body mass, maximal and relative strength of climbers and control group

\begin{tabular}{|c|c|c|c|c|c|c|c|}
\hline \multirow[b]{2}{*}{ Parameter } & \multirow[b]{2}{*}{ Participants } & \multirow[b]{2}{*}{ Mean } & \multirow[b]{2}{*}{ SD } & \multicolumn{2}{|c|}{ Confidence interval } & \multirow[b]{2}{*}{$\mathbf{p}$} & \multirow[b]{2}{*}{$\eta 2$} \\
\hline & & & & $\begin{array}{c}\text { Lower } \\
\text { limit }\end{array}$ & $\begin{array}{l}\text { Upper } \\
\text { limit }\end{array}$ & & \\
\hline \multirow{2}{*}{$\begin{array}{c}\text { Body mass } \\
(\mathrm{kg})\end{array}$} & Control group (n 7) & 81.43 & 13.14 & 69.28 & 93.58 & \multirow{2}{*}{$0.016^{\star}$} & \multirow{2}{*}{0.351} \\
\hline & Sport climbers (n 9) & 67.87 & 6.18 & 63.12 & 72.63 & & \\
\hline \multirow{2}{*}{$\begin{array}{c}\text { Maximal } \\
\text { strength }(\mathrm{N})\end{array}$} & Control group (n 7) & 338 & 55 & 286 & 389 & \multirow{2}{*}{0.372} & \multirow{2}{*}{0.057} \\
\hline & Sport climbers (n 9) & 313 & 52 & 273 & 353 & & \\
\hline \multirow{2}{*}{$\begin{array}{l}\text { Relative } \\
\text { strength }\end{array}$} & Control group (n 7) & 4.2 & 0.8 & 3.5 & 4.9 & \multirow{2}{*}{0.263} & \multirow{2}{*}{0.089} \\
\hline & Sport climbers (n 9) & 4.6 & 0.6 & 4.1 & 5.1 & & \\
\hline
\end{tabular}

Relative strength, maximal strength $(N)$ related to body mass $(\mathrm{kg}) ; \mathrm{SD}$, standard deviation*, significant differences $(p<0.05)$.

Table 2. Performance characteristics in the endurance tests at different intensity of isometric muscle contraction

\begin{tabular}{|c|c|c|c|c|c|c|c|c|}
\hline \multirow{2}{*}{$\begin{array}{c}\% \\
\text { MVC }\end{array}$} & \multirow[b]{2}{*}{ Parameter } & \multirow[b]{2}{*}{ Participants } & \multirow[b]{2}{*}{ Mean } & \multirow[b]{2}{*}{ SD } & \multicolumn{2}{|c|}{ Confidence interval } & \multirow[b]{2}{*}{$\mathbf{p}$} & \multirow[b]{2}{*}{$\eta 2$} \\
\hline & & & & & $\begin{array}{c}\text { Lower } \\
\text { limit }\end{array}$ & $\begin{array}{l}\text { Upper } \\
\text { limit }\end{array}$ & & \\
\hline \multirow{6}{*}{90} & \multirow{2}{*}{$\operatorname{Ttz}(\mathrm{s})$} & $\begin{array}{c}\text { Control group } \\
\text { (n 7) }\end{array}$ & 16.63 & 7.02 & 9.26 & 23.99 & \multirow{2}{*}{.664} & \multirow{2}{*}{.015} \\
\hline & & $\begin{array}{l}\text { Sport climbers } \\
\text { (n 9) }\end{array}$ & 18.20 & 6.52 & 13.19 & 23.21 & & \\
\hline & \multirow{2}{*}{ FTI (N.s) } & $\begin{array}{c}\text { Control group } \\
\text { (n 7) }\end{array}$ & 4182 & 1975 & 2110 & 6255 & \multirow{2}{*}{.782} & \multirow{2}{*}{.006} \\
\hline & & $\begin{array}{l}\text { Sport climbers } \\
\text { (n 9) }\end{array}$ & 4449 & 1663 & 3171 & 5727 & & \\
\hline & \multirow{2}{*}{$\begin{array}{l}\text { FTI/kg } \\
\text { (N.s/kg) }\end{array}$} & $\begin{array}{c}\text { Control group } \\
\text { (n } 7)\end{array}$ & 53.04 & 23.01 & 28.89 & 77.18 & \multirow{2}{*}{.358} & \multirow{2}{*}{065} \\
\hline & & $\begin{array}{l}\text { Sport climbers } \\
\text { (n 9) }\end{array}$ & 66.57 & 29.13 & 44.18 & 88.96 & & \\
\hline
\end{tabular}




\begin{tabular}{|c|c|c|c|c|c|c|c|c|}
\hline \multirow{6}{*}{70} & \multirow{2}{*}{$\operatorname{Ttz}(s)$} & $\begin{array}{l}\text { Control group } \\
\text { (n 7) }\end{array}$ & 27.98 & 7.13 & 21.38 & 34.57 & \multirow{2}{*}{.044} & \multirow{2}{*}{.259} \\
\hline & & $\begin{array}{l}\text { Sport climbers } \\
\text { (n 9) }\end{array}$ & 38.51 & 10.85 & 30.17 & 46.85 & & \\
\hline & \multirow{2}{*}{ FTI (N.s) } & $\begin{array}{l}\text { Control group } \\
\text { (n 7) }\end{array}$ & 6095 & 1651 & 4568 & 7622 & \multirow{2}{*}{.224} & \multirow{2}{*}{.104} \\
\hline & & $\begin{array}{l}\text { Sport climbers } \\
\text { (n 9) }\end{array}$ & 7262 & 1933 & 5776 & 8748 & & \\
\hline & \multirow{2}{*}{$\begin{array}{l}\text { FTI/kg } \\
\text { (N.s/kg) }\end{array}$} & $\begin{array}{l}\text { Control group } \\
\text { (n 7) }\end{array}$ & 75.18 & 17.63 & 58.88 & 91.49 & \multirow{2}{*}{.018} & \multirow{2}{*}{.338} \\
\hline & & $\begin{array}{l}\text { Sport climbers } \\
\text { (n 9) }\end{array}$ & 106.96 & 27.24 & 86.02 & 127.90 & & \\
\hline \multirow{6}{*}{50} & \multirow{2}{*}{$\mathrm{Ttz}(\mathrm{s})$} & $\begin{array}{c}\text { Control group } \\
(\mathrm{n} 7)\end{array}$ & 48.01 & 5.87 & 42.58 & 53.44 & \multirow{2}{*}{.050} & \multirow{2}{*}{.248} \\
\hline & & $\begin{array}{l}\text { Sport climbers } \\
\text { (n 9) }\end{array}$ & 57.29 & 10.15 & 49.49 & 65.1 & & \\
\hline & \multirow{2}{*}{ FTI ( } & $\begin{array}{l}\text { Control group } \\
\text { (n 7) }\end{array}$ & 7771 & 1599 & 6292 & 9251 & \multirow{2}{*}{.921} & \multirow{2}{*}{.001} \\
\hline & & $\begin{array}{l}\text { Sport climbers } \\
\text { (n 9) }\end{array}$ & 7880 & 2443 & 6002 & 9758 & & \\
\hline & \multirow{2}{*}{$\begin{array}{l}\text { FTI/kg } \\
\text { (N.s/kg) }\end{array}$} & $\begin{array}{c}\text { Control group } \\
(\mathrm{n} 7)\end{array}$ & 96.92 & 22.58 & 76.03 & 117.81 & \multirow{2}{*}{.238} & \multirow{2}{*}{.098} \\
\hline & & $\begin{array}{l}\text { Sport climbers } \\
\text { (n 9) }\end{array}$ & 115.77 & 35.05 & 88.82 & 142.71 & & \\
\hline \multirow{6}{*}{30} & \multirow{2}{*}{$\operatorname{Ttz}(\mathrm{s})$} & $\begin{array}{l}\text { Control group } \\
\text { (n 7) }\end{array}$ & 102.38 & 40.33 & 65.08 & 139.68 & \multirow{2}{*}{.251} & \multirow{2}{*}{.093} \\
\hline & & $\begin{array}{l}\text { Sport climbers } \\
\text { (n 9) }\end{array}$ & 126.94 & 41.02 & 95.41 & 158.47 & & \\
\hline & \multirow{2}{*}{ FTI (N.s) } & $\begin{array}{c}\text { Control group } \\
(\mathrm{n} 7)\end{array}$ & 8491 & 2044 & 6601 & 10382 & \multirow{2}{*}{.354} & \multirow{2}{*}{.061} \\
\hline & & $\begin{array}{l}\text { Sport climbers } \\
\text { (n 9) }\end{array}$ & 10322 & 4695 & 6713 & 13931 & & \\
\hline & \multirow{2}{*}{$\begin{array}{l}\text { FTI/kg } \\
\text { (N.s/kg) }\end{array}$} & $\begin{array}{l}\text { Control group } \\
\text { (n 7) }\end{array}$ & 107.92 & 36.06 & 74.57 & 141.27 & \multirow{2}{*}{.132} & \multirow{2}{*}{.154} \\
\hline & & $\begin{array}{l}\text { Sport climbers } \\
\text { (n 9) }\end{array}$ & 150.68 & 62.94 & 102.30 & 199.06 & & \\
\hline
\end{tabular}

$\% M V C$, relative intensity - percentage of maximal voluntary contraction; Ttz, time spent in the force target zone ( $\pm 10 \%$ target force); FTI, force-time integral; FTI/kg, force-time integral (N), related to body mass ( $\mathrm{kg})$; $S D$, standard deviation. 


\section{DISCUSSION}

A new finding is that elbow flexor muscle endurance time at $70 \%$ and $50 \%$ MVC is a distinguishing ability with sports climbers. Nevertheless, it seems that climbers' elbow flexor muscle performance at $70 \% \mathrm{MVC}$ is the most important because the largest effect size was found for FTI related to body mass in the endurance test at $70 \%$ MVC. It is known that FTI compared to test time is a better measure of climbing specific intermittent finger flexor endurance (MacLeod et al., 2007). The highest effect size of the difference between the climbers from the present study and the control group was found for FTI related to body mass in the test at 70\% MVC (Table 2). This can be explained with the fact that FTI related to body mass carries information about both endurance and strength components as well as better reflects the specificity of climbing activity, because climbers have to overcome their weight in order to progress on the route.

$70 \% \mathrm{MVC}$ is an intensity, at which part of IIx muscle fibers and a large portion of IIa muscle fibers are recruited (Hannerz 1974). The present results show that climbers are adapted to exercise in such conditions. The present findings are in conformity with the findings of Esposito et al.(2009) who concluded that there is a shift of climbers' finger flexor muscles toward faster motor units.

The present study also shows that climbing demands a high level of elbow flexor endurance. However, an excessive increase of this ability would not necessarily lead to a significant improvement in climbing performance. This is evidenced by the lack of significant correlations between the measured parameters in the elbow flexor endurance tests and climb- ing achievements in the red point and onsight styles.

Unlike climbers' endurance tests results, elbow maximal strength related to body mass significantly correlated with climbing performance. It can be assumed that increasing elbow flexor strength while possessing high levels of other abilities of major importance (such as finger strength and endurance) will improve climbing performance. However, climbers elbow flexor maximal strength test results were not higher compared to the control group and climbers' elbow flexors may not be stronger than elbow flexors of other athletic populations. Previous studies suggested that elbow flexor maximal strength is a key performance factor in sports climbing. The authors of these studies conducted tests, which involve simultaneous action of arm, shoulder and back muscles. Wall et al. (2004) found moderate $(\mathrm{r} \sim 0.6)$ and Kodejška and Baláš (2016) found strong $(r=0.76)$ correlations between climbing ability and results from shoulder girdle strength tests. Furthermore, other studies showed that explosive strength of the upper limbs assessed through powerful pull-ups is also an important ability in sports climbing (Berrostegieta, 2006; Draper et al., 2011; Laffaye et al., 2014). The participants in these latter studies had to reach with one or both hands as high as possible and the score in $\mathrm{cm}$ correlated strongly with climbing ability $(\mathrm{r} \sim 0.7)$ (Draper et al., 2011; Laffaye et al., 2014).

Different types of muscle fibers are activated depending on the intensity of muscle contractions (Hannerz 1974). Intensity will determine to which type of muscle fibers the training is directed and the training effect (i.e. maximal strength, intra-muscular coordination, muscle hy- 
pertrophy, muscle endurance). There is a nonlinear relationship between intensity and maximum duration of isometric muscle contractions (Rohmert, 1960). Thus, intensity can be predicted during training using the maximum time for which the athlete is able to maintain a static position. The use of generalized models of the intensity-duration relationship of isometric muscle contractions cannot precisely prescribe isometric exercise in accordance with the training goal of an athlete in a specific sports discipline. This relationship is different for different populations and muscle groups (Avin, Law, 2011, Law,Avin 2010). The present study provides information (duration of muscle contraction at different intensities, Table 2) about optimizing the training of elbow flexor muscle strength and endurance during isometric exercise in climbing.

The authors acknowledge that the sample size in the climbing and control groups limit the performance of thorough statistical analysis. Therefore, it cannot be claimed that the results of the present study are valid for the entire climbing population. Further studies with larger

\section{REFERENCES}

Avin, K.G., Law, L.A. (2011), Agerelated differences in muscle fatigue vary by contraction type: a meta-analysis, Physical Therapy,Vol. 91 No. 8, pp. 1153-1165.

Baláš, J., Michailov, M., Giles, D., Kodejška, J., Panáčková, M., \& Fryer, S. (2016), Active recovery of the finger flexors enhances intermittent handgrip performance in rock climbers, European Journal of Sport Science, Vol. 16 No. 7, pp. 764-772. samples of not only male but also female participants of all ages and climbing ability levels should be conducted to confirm the $p$ resent findings. Fatigue might have prevented participants, especially the less trained, from fully realizing their maximal potential in the last muscle endurance tests. However, the breaks between these tests (20 minutes) were considered optimal based on a pilot study, which showed that blood lactate concentration is reduced to rest level 15 minutes after completing a muscle endurance test at medium intensity $(50-70 \% \mathrm{MVC})$.

\section{CONCLUSION}

Elbow flexor strength and endurance appear to be key performance factors in sports climbing. Climbers should concentrate on training elbow flexor endurance at high intensities. Excessive development of elbow flexor endurance is not necessary. However, higher climbing ability demands increased elbow flexor maximal strength. The present results may be useful to precisely prescribe training of elbow flexor strength and endurance when climbers use isometric exercise.

Baláš, J., Pecha, O., Martin, A.J., Cochrane, D. (2012), Hand-arm strength and endurance as predictors of climbing performance, European Journal of Sport Science, Vol. 12 No. 1, pp. 16-25.

Baláš, J., Mrskoc`, J., Panác ková, M., \& Draper, N. (2015), Sportspecific finger flexor strength assessment using electronic scales in sport climbers, Sports Technology, doi:10.1080/19346182. 2015.1012082

Berrostegieta. J.I. (2006), Relation between specific force tests and chained degree in high level sport climbers, in: 
Moritz EF, Haake S, ed. The engineering of Sport 6, Volume 2. Developments for disciplines. New York Springer Science and Business Media.

Deyhle, M.R., Hsu, H.S., Fairfield, T.J., Cadez-Schmidt, T.L., Gurney, B.A., Mermier, C.M. (2015), Relative importance of four muscle groups for indoor rock climbing performance, The journal of Strength and Conditioning Research,Vol. 29 No. 7, pp. 2006-2014.

Draper, N., Dickson, T., Blackwell, G., Priestley, S., Fryer, S., Marshall, H., et al. (2011), Sport-specific power assessment for rock climbing, Journal of Sports Medicine and Physical Fitness, Vol. 51 No. 3, pp. 417-425.

Draper, N., Giles, D., Schöffl, V., Fuss, F., Watts, P., Wolf, P., Abreu, E. (2015), Comparative grading scales, statistical analyses, climber descriptors and ability grouping: International Rock Climbing Research Association Position Statement, Sport Technology, doi:10.1080/19346182.2015.1107081

Esposito, F., Limonta, E., Cè, E., Gobbo, M., Veicsteinas, A., Orizio, C. (2009), Electrical and mechanical response of finger flexor muscles during voluntary isometric contractions in elite rock-climbers, European Journal of Applied Physiology, Vol. 105 No. 1, pp. 81-92.

Fryer, S., Stoner, L., Lucero, A., Witter, T., Scarrott, C., Dickson, T., Cole, M., Draper, N. (2015), Haemodynamic kinetics and intermittent finger flexor performance in rock climbers, International Journal of Sports Medicine, Vol. 36 No. 2, pp. 137-142.

Grant, S., Hynes, V., Whittaker, A., Aitchison, T. (1996), Anthropometric, strength, endurance and flexibility characteristics of elite and recreational climbers, Journal of Sports Sciences, Vol. 14 No. 4, pp. 301-309.

Hannerz, J. (1974), Discharge properties of motor units in relation to recruitment order in voluntary contraction. Acta Physiologica Scandinavica, Vol. 91 No. 3, pp. 374-384.

Law, L.A., Avin, K.G. (2010), Endurance time is joint-specific: a modelling and meta-analysis investigation, Ergonomics, Vol. 53 No. 1, pp. 109-129.

Kodejška, J., Baláš, J. (2016), Shoulder girdle strength and finger flexor strength in prediction of performance in female rock climbers, Studia Sportiva, Vol. 10 No. 2, pp. 46-54.

Koukoubis, T.D., Cooper, L.W., Glisson, R.R., et al. (1995), An electromyographic study of arm muscles during climbing, Knee Surgery, Sports Traumatology, Arthroscopy, Vol. 3 No. 2, pp. 3: 121-124.

Laffaye, G., Collin, J.M., Levernier, G., Padulo, J. (2014), Upper-limb power test in rock-climbing, International Journal of Sports Medicine, Vol. 35 No. 8, pp. 670-675.

MacLeod, D., Sutherland, D.L., Buntin, L., Whitaker, A., Aitchison, T., Watt, I., Bradley, J., Grant, S. Physiological determinants of climbing-specific finger endurance and sport rock climbing performance, Journal of Sports Sciences, Vol. 25 No. 12, pp. 1433-1443.

Michailov, M., Rokowski, R., Ręgwelski, T., Staszkiewicz, R., Szygula, Z., Brown, L. (2017), Physiological Responses During Two Climbing Tests With Different Hold Types, International Journal of Sports Science \& Coaching, Vol. 12 No. 2, pp. 276-283.

Michailov, M.L., Mladenov, L.V., 
Schoeffl, V.R. (2009), Anthropometric and strength characteristics of worldclass boulderers, Medicina Sportiva, Vol. 13 No. 4, pp. 231-238.

Michailov, M.L. (2014), Workload characteristic, performance limiting factors and methods for strength and endurance training in rock climbing, Medicina Sportiva,Vol. 18 No. 3, pp. 97-106.

Noé, F., Quiane, F., Martin, L. (2001), Influence of steep gradient supporting walls in rock climbing: Biomechanical analysis. Gait and Posture 2001, Vol. 13 No. 2, pp. 86-94.

Philippe, M., Wegst, D., Muller, T., Raschner, C., \& Burtscher, M. (2012), Climbing-specific finger flexor performance and forearm muscle oxygenation in elite male and female sport climbers, European Journal of Applied Physiology, Vol. 112 No. 8, pp. 2839-2847.

Phillips, K.C., Sassaman, J.M., Smoliga, J.M. (2012), Optimizing Rock
Climbing Performance Through SportSpecific Strength and Conditioning, Strength \& Conditioning JournalVol. 34 No. 3, pp. 1-18.

Rohmert, W. (1960), Determination of the recovery pause for static work of man. Internationale Zeitschrift Fur Angewandte Physiologie, Einschliesslich Arbeitsphysiologie, Vol. 18, pp. 123164.

Vigouroux, L., Quaine, F. (2006), Fingertip force and electromyography of finger flexor muscles during a prolonged intermittent exercise in elite climbers and sedentary individuals. Journal of Sports Sciences, Vol. 24 No. 2, pp. 181-186.

Wall, C.B., Starek, J.E., Fleck, S.J., and Byrnes, W.C. (2004), Prediction of indoor climbing performance in women rock climbers. The journal of Strength and Conditioning Research, Vol. 18 No. 1, pp. 77-83.

Correspondence:

Michail Michailov National Sports Academy Vassil Levski”, Sofia, Bulgaria E-mail: michailovi@hotmail.com 